\title{
Association of Epstein-Barr virus with human mammary carcinoma. Pros and cons
}

\author{
Robert Touitou ${ }^{\mathrm{b}}$, \\ Mathide Bonnet-Duquenoy ${ }^{\mathrm{a}}$ and Irène Joab ${ }^{\mathrm{a}, *}$ \\ a INSERM, Hôpital Saint Louis, 27 rue Juliette Dodu, \\ Paris, France \\ ${ }^{\mathrm{b}}$ Ludwig Institute for Cancer Research, London, UK
}

\begin{abstract}
The Epstein-Barr virus (EBV) is associated with the development of different malignancies. In the last few years, EBV has been detected in a subset of breast tumors. The EBV genome was detected by PCR and Southern-blot analysis and identification of the infected cells was determined using different in situ methods. EBV has detected more frequently in steroid hormone receptors negative tumors, in high histological SBR grade tumors and furthermore, the EBV genome was also observed in metastatic lymph nodes, along with EBV detection in the primary tumor. Opposing results are discussed.
\end{abstract}

\section{Introduction}

The Epstein-Barr virus (EBV) is associated with the development of different malignancies such as Burkitt's lymphoma, nasopharyngeal carcinoma (NPC) [11] and carcinomas in various organs $[3,10,14]$. In the last few years, EBV has been detected in a subset of breast tumors and reported in different studies $[1,7,8]$. To this aim, different approaches were used. The EBV genome was detected by PCR and Southern-blot analysis and identification of the infected cells was determined using various in situ techniques.

\section{Investigation of the presence of the EBV genome by PCR in breast cancer, healthy tissue and} lymph node metastasis

In three separate studies, PCR techniques allowed the detection of the virus genome in $20-51 \%$ of in-

*Address for correspondence: Tel.: +331 424992 68; Fax: +33 1424948 38; E-mail: i.joab@chu-stlouis.fr. vasive breast carcinoma of different histological types whereas no or only rare positive cases was obtained with healthy tissue $[1,7,8]$. These results suggest that $\mathrm{EBV}$ is restricted to the tumor.

However, a study performed with samples collected over a period of 30 years failed to detect the EBV genome in 34 breast carcinomas (including 16 medullary carcinoma) [4]. Negative results could be due to differences in the preparation of samples (fixation, storing) over such a long period of time.

Investigation of lymph nodes with metastasis suggested that EBV could already be present in the tumor cells prior to their migration [1].

\section{EBV presence and breast cancer prognostic factors}

We also observed a statistically significant relationship between EBV presence and several poor prognostic factors for breast carcinomas, such as, steroid hormone receptors negative, high histological SBR grade, and association with axillary node invasion [1]. Findings which suggest that the infection by EBV may be related to a high metastatic potential of the tumor.

\section{Breast cancer and EBV: Identification of the infected cells}

The direct detection of EBV products had to be addressed. In situ hybridization (ISH) with EBER-1 (Epstein-Barr virus encoded small RNA1) probes, a very sensitive method for the detection of EBV in infected cells, is widely used because of the high EBER RNA copy number. EBER-1 were identified on frozen sections, in a fraction of malignant cells in six different breast tumors [7] while in other studies using paraffin sections, EBER-1 transcripts could not be detected $[1,2,5,8]$. Technical problems (related to tissue fixation, probe penetration in breast tissue) may be responsable for the negative results. In addition, the 
regulation of transcription of EBERs remains poorly understood and their high expression in infected cells might not be universal. NPC which exhibits varying degrees of differentiation lacks EBERs expression in some areas [9]. Moreover Takeuchi et al. [12] did not observe any EBER-1 expression in some EBV-positive NPC cases. Contrary to the other EBV associated diseases, it appears that EBERs ISH is not the best method for identifying infected cells in breast cancers.

Immunohistochemical studies were performed on 60 invasive breast cancers collected and processed 11 to 20 years ago [2]. The authors did not detect the latent membrane protein 1 (LMP-1) although, in a previous study, [8] a distinct staining for LMP-1 was observed in scattered epithelial cells in several of the tumor sections examined. The fact that few cells were stained, the low sensitivity of immunochemistry and the epidemiologic difference of the samples analyzed could explain the divergence between these two results. The EpsteinBarr nuclear antigen 2 (EBNA-2) was not detected in the breast carcinoma samples [2]. This result is coherent with all in vivo studies which show that EBNA2 is not expressed in EBV associated tumors. This antigen is only expressed in lymphoproliferative disorders and lymphomas of immunodeficient patients [11].

EBNA1 is essential for the maintenance of the viral episome in infected cells and is constantly expressed in all EBV infections [11]. EBNA-1, has been detected in breast cancer tumor cells by immunohistochemistry [ 1 , 6]. Monoclonal antibodies distinctly showed nuclear staining of many epithelial tumor cells while normal cells (including lymphocytes) were not labeled. The fact that only a fraction of tumor cells were found to be EBNA-1 positive in breast cancer could reflect low expression or low accessibility of the protein to staining in some cells. Alternatively, at this stage of the disease, the virus may have been lost in a fraction of those cells.

RT-PCR analysis of cDNAs encoding the EBNA1 protein could be detected in a series of EBV positive infiltrating breast cancers and not in EBV negative samples (Boualaga and Joab, unpublished results). EBNA1 is able to induce malignancies in transgenic mice by a mechanism which is not yet understood [13]. The expression of EBNA-1 in breast tumors might be important in the transformation phenomenon.

\section{Conclusion}

The discrepancies between results need to be resolved since an association of EBV with breast cancer have potential relevance to its early detection, treatment and even prevention. This implies the need for more studies. As positive results are more conclusive that negative ones, it would appear that, PCR of comparable efficiency should be performed on frozen material with an appropriate single copy gene of the cellular genome as a control. Optimized RT-PCR conditions should be used for detection of EBV transcripts. In situ methods have to be developed to confirm the already published work. The proportion of EBV-infected breast tumor cells, would have to be confirmed by sensitive techniques (ie in situ PCR). Real time PCR on microdissected tumors cells would be a valuable tool for the determination of the number of EBV genome copies per cell.

The question of EBV as an etiologic factor remains to be answered. Howewer, it could still be a useful prognostic marker or provide molecular targets for therapy.

\section{Note added in proof}

While this review was in press, Fina et al. (Br J Cancer 84 (2001) 783-790) described the presence of EBV in a large subset of breast cancer. Moreover, EBER ISH was found to be positive in a fraction of tumor cells.

\section{Acknowledgements}

We are grateful to Dr. Alberga for careful reading of the manuscript. This project was supported by ARC 5512 .

\section{References}

[1] M. Bonnet, J.M. Guinebretiere, E. Kremmer, V. Grunewald, E. Benhamou, G. Contesso and I. Joab, Detection of EpsteinBarr virus in invasive breast cancers, J. Natl. Cancer Inst. 91 (1999), 1376-1381.

[2] J.S. Chu, C.C. Chen and K.J. Chang, In situ detection of Epstein-Barr virus in breast cancer, Cancer Lett. 124 (1998), 53-57.

[3] I.W. Dimery, J.S. Lee, M. Blick, G. Pearson, G. Spitzer and W.K. Hong, Association of the Epstein-Barr virus with lymphoepithelioma of the thymus, Cancer 61 (1988), 2475-2480.

[4] M.J. Gaffey, H.F. Frierson, S.E. Mills, J.C. Boyd, R.J. Zarbo, J.F. Simpson, L.K. Gross and L.M. Weiss, Identification of lymphocyte subpopulation and their significance, Modern. Pathol 6 (1993), 721-728. 
[5] S.L. Glaser, R.F. Ambinder, J.A. Digiuseppe, P.L. Hornross and J.L. Hsu, Absence of Epstein-Barr virus EBER-1 transcripts in an epidemiologically diverse group of breast cancers, Int J Cancer 75 (1998), 555-558.

[6] F.A. Grasser, P.G. Murray, E. Kremmer, K. Klein, K. Remberger and W. Feiden et al., Monoclonal antibodies directed against the Epstein-Barr virus-encoded nuclear antigen 1 (EBNA1): Immunohistologic detection of EBNA1 in the malignant cells of Hodgkin's disease, Blood 84 (1994), 3792 3798.

[7] L.G. Labrecque, D.M. Barnes, I.S. Fentiman and B.E. Griffin, Epstein-Barr virus in epithelial cell tumors: A breast cancer study, Cancer Res 55 (1995), 39-45.

[8] Y.A Luqmani and S. Shousha, Presence of Epstein-Barr virus in breast carcinoma, Int J Oncol 6 (1995), 899-903.

[9] R. Pathmanathan, U. Prasad, G. Chandrika, R. Sadler, K. Flynn and N. Raabtraub, Undifferentiated, nonkeratinizing, and squamous cell carcinoma of the nasopharynx: Variants of Epstein-Barr virus-infected neoplasia, Am J Pathol 146 (1995), 1355-1367.
[10] N. Raab-Traub, P. Rajadurai, K. Flynn and A.P. Lanier, Epstein-Barr virus infection in carcinoma of the salivary gland, J Virol 65 (1991), 7032-7036.

[11] A.B. Rickinson and E. Kieff, Epstein-Barr virus, in: Virology, B.N. Fields, D.M. Knipe AND A.L. Howley Et, eds, Lippincott-Raven Press, Philadelphia, 1996, pp. 2397-2446.

[12] H. Takeuchi, R. Kobayashi, M. Hasegawa and K. Hirai, Detection of latent Epstein-Barr virus (EBV) DNA in paraffin sections of nasopharyngeal carcinomas expressing no EBVencoded small RNAs using in situ PCR, Arch Virol 142 (1997), $1743-1756$.

[13] J.B. Wilson, J.L. Bell and A.J. Levine, Expression of EpsteinBarr virus nuclear antigen-1 induces B cell neoplasia in transgenic mice, EMBO J 15 (1996), 3117-3126.

[14] M.P. Wong, L.P. Chung, S.T. Yuen, S.Y. Leung, S.Y. Chan and E. Wang et al., In situ detection of Epstein-Barr virus in non small cell lung carcinomas, J Pathol 177 (1995), 233-240. 


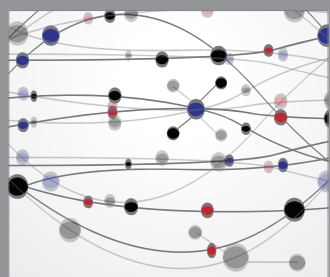

The Scientific World Journal
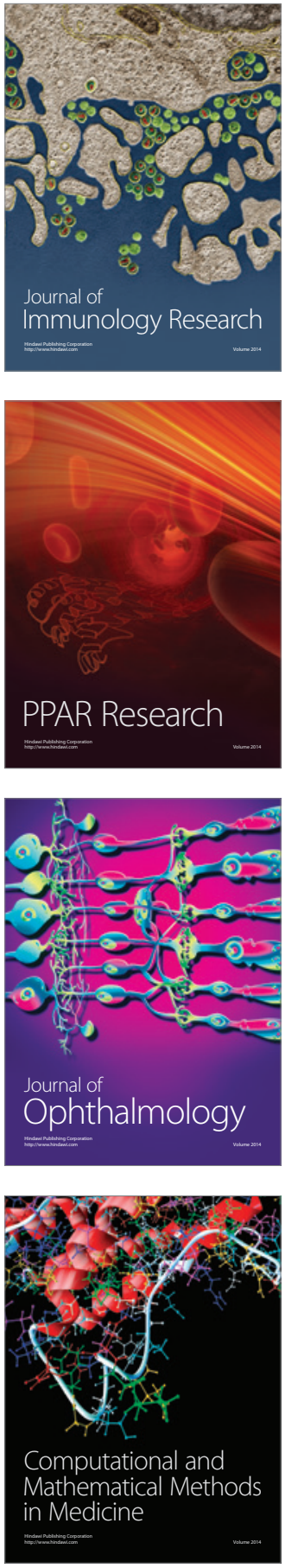

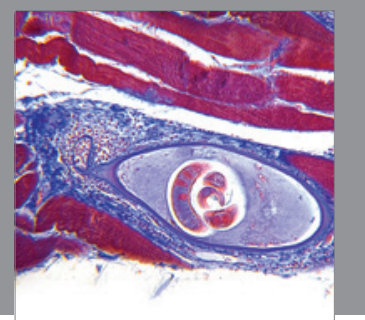

Gastroenterology

Research and Practice
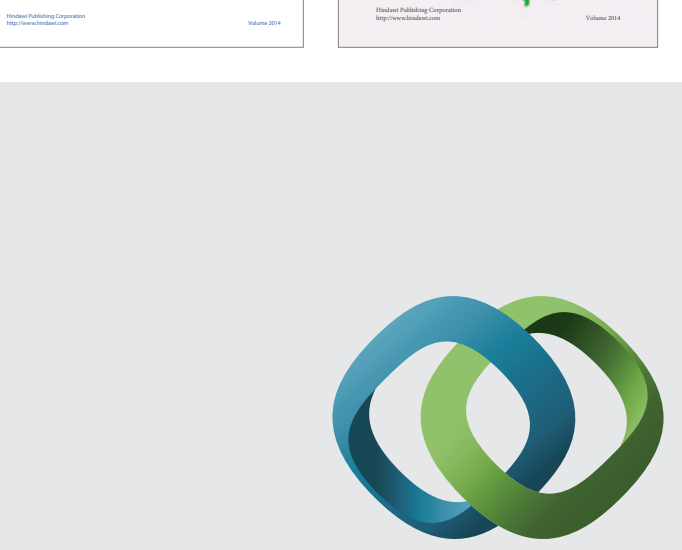

\section{Hindawi}

Submit your manuscripts at

http://www.hindawi.com
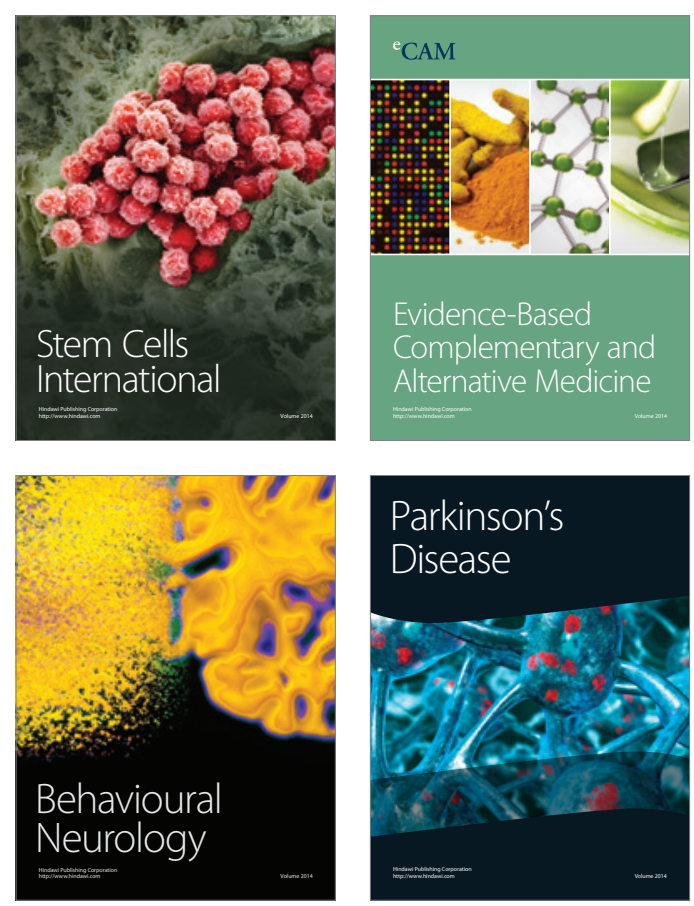

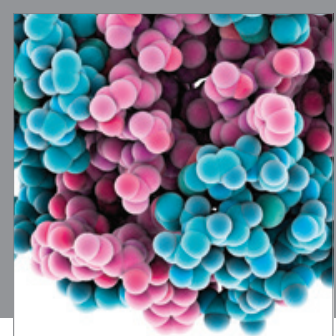

Journal of
Diabetes Research

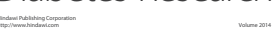

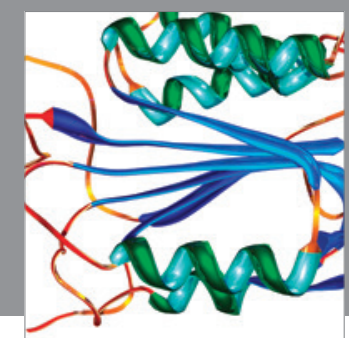

Disease Markers
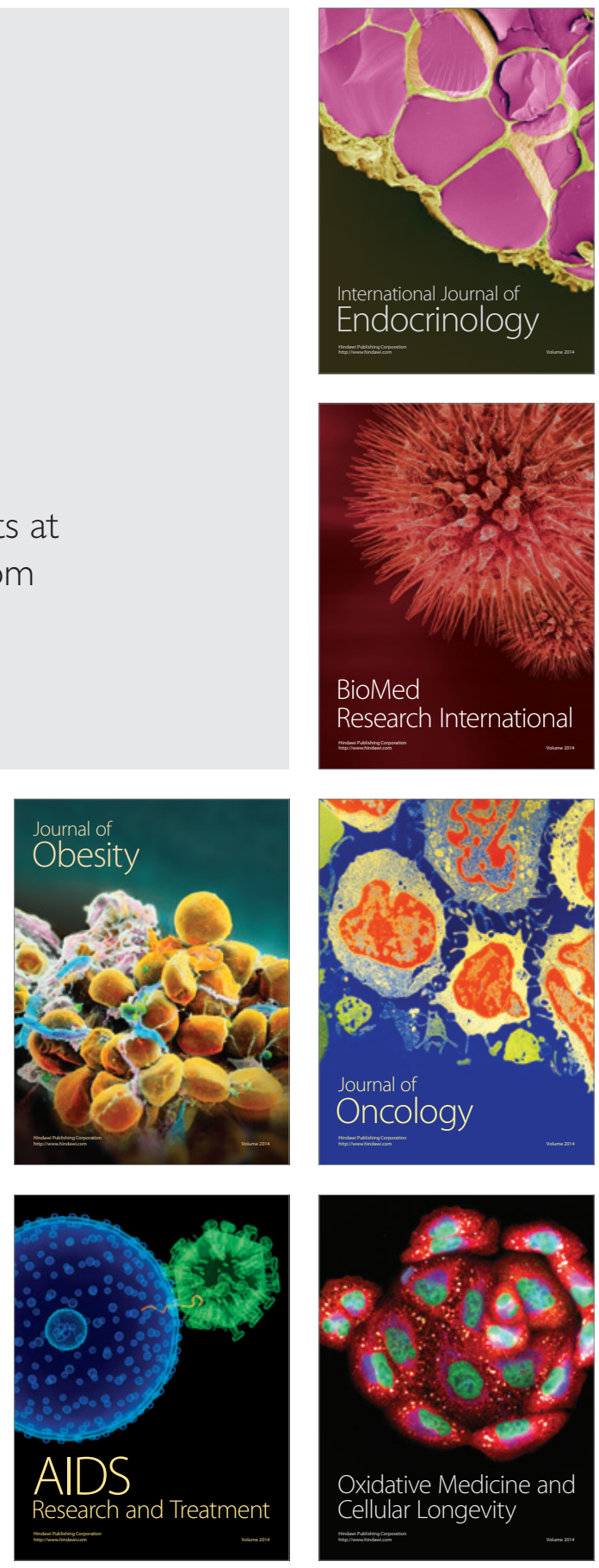